\title{
CASTANHA TIPO PORTUGUESA NO BRASIL ${ }^{1}$
}

\author{
SILVANA CATARINA SALES BUENO² \& RAFAEL PIO ${ }^{3}$
}

RESUMO- Frutífera originária do Hemisfério Norte, a castanheira pertence à família das Fagaceae. O gênero Castanea apresenta sete espécies, das quais se destacam C. sativa Miller, C. crenata Siebold \& Zucc., C. molissima Blume e C. dentata (Marsh.) Borkh. Tais espécies receberam denominações de acordo com o local de origem e são conhecidas, respectivamente, por castanha-portuguesa (Portugal), castanhajaponesa (Japão e Coreia do Sul), castanha-chinesa (China) e castanha-americana (América do Norte). Dada sua relevância como uma das mais importantes espécies frutícolas da antiguidade, as castanhas mantêm a tradição de consumo nas festas natalinas e, por conta de suas qualidades nutritivas e por ser um produto versátil, servem o ano todo, em alguns países, como alimento para pessoas e animais. O Núcleo de Produção de Mudas de São Bento do Sapucaí mantém uma coleção com algumas cultivares e seleção e, em parceria com a Universidade Federal de Lavras (UFLA), vem estudando essa fruteira, que possui grande potencial para a fruticultura brasileira.

Termos para Indexação: Castanea crenata x Castanea sp., florescimento, produção.

\section{CHESTNUT IN BRAZIL}

\begin{abstract}
Fruitful originated in the Northern Hemisphere, the chestnut belongs to the Fagaceae family. The Castanea genus has seven species of which stand out $C$. sativa Miller, C. crenata Siebold \& Zucc., C. molissima Blume and $C$. dentata (Marsh.) Borkh. The species have received names according to their place of origin and are known respectively by chestnut (Portugal), Japanese chestnut (Japan and Korea), Chinese chestnut (China) and American chestnut (North America). Given the importance as one of the most important fruit species of antiquity, chestnuts maintain the tradition of Christmas celebrations in consumption and because of its nutritional qualities and being a versatile product it has been offered throughout the year, in some countries, as food for people and animals. In São Bento do Sapucaí, at the Fruit Tree Nursery Center, Extension Service, São Paulo Agricultural Station (CATI - SAA / SP - NPM-SBS), there is a collection with some cultivars and selection. In partnership with the Universidade Federal de Lavras (UFLA), the chestnut has been studied due to its great potential as a Brazilian fruit production.
\end{abstract}

Index Terms: Castanea crenata x Castanea sp., flowering, production.

\section{INTRODUÇÃO}

Frutífera originária do Hemisfério Norte, a castanheira pertence à família das Fagaceae. O gênero Castanea apresenta sete espécies, das quais se destacam C. sativa Miller, C. crenata Siebold \& Zucc., C. molissima Blume e C. dentata (Marsh.) Borkh. Tais espécies receberam denominações de acordo com o local de origem e são conhecidas, respectivamente, por castanha-portuguesa (Portugal), castanha-japonesa (Japão e Coreia do Sul), castanhachinesa (China) e castanha-americana (América do Norte) (MAYNARD et al., 2008).
Dada sua relevância como uma das mais importantes espécies frutícolas da antiguidade, as castanhas mantêm a tradição de consumo nas festas natalinas. A castanheira produz ouriços em cujo interior se encontram as sementes ou amêndoas - parte comestível - que podem ser consumidas nas mais variadas formas (natural, cozida, assada, açucarada, cristalizada ou seca na forma de farinha para o preparo de pães, bolos e doces). O nobre produto francês marron glacé, elaborado a partir das amêndoas inteiras e levemente açucaradas, tem o sabor classificado como um dos melhores e mais delicados do mundo. Além disso, as castanhas vêm

\footnotetext{
1(Trabalho 442-13). Recebido em: 20-09-2013. Aceito para publicação em: 15-12-2013. Palestra II Simpósio Internacional de Fruticultura- Frutas Exóticas, 21 a 25 de outubro de 2013. Jaboticabal-SP.

${ }^{2}$ Engenheira Agrônoma, D.Sc., Secretaria da Agricultura e Abastecimento do Estado de São Paulo, Coordenadoria de Assistência Técnica Integral - CATI, Núcleo de Produção de Mudas de São Bento do Sapucaí, -Caixa Postal 22, 12490-000, São Bento do Sapucaí-SP. scsbueno@cati.sp.gov.br

${ }^{3}$ Engenheiro Agrônomo, D.Sc., Professor do Depto. de Agricultura, Universidade Federal de Lavras - UFLA, Caixa Postal 3037,
} 37200-000, Lavras-MG. rafaelpio@dag.ufla.br 
sendo incorporadas na gastronomia de alto padrão (BUENO, 2004).

A castanha tipo portuguesa, como é conhecida no Brasil, desempenhou um papel importante na história da humanidade, por conta de suas qualidades nutritivas e por ser um produto versátil, servindo o ano todo como alimento para pessoas e animais. $\mathrm{Na}$ colonização da América, a castanha-americana ( $C$. dentata) era a árvore principal, fornecendo madeira para dormentes, molduras, casa, celeiros, cercas, combustível e tanino para processamento de couro.

O cultivo da castanheira pode ser impulsionado por representar uma alternativa viável à diversificação agrícola face às inúmeras possibilidades de uso de suas amêndoas, rusticidade da planta, baixo custo para a manutenção do pomar e pouca utilização de mão de obra (BUENO, 2004), podendo ser, nesse caso, uma opção ao cultivo de nozes e amêndoas em São Paulo, que hoje está embasado da produção da nogueira-macadâmia (PENONI et al., 2011; MARO et al., 2012).

\section{PRODUÇÃO MUNDIAL DE CASTANHA}

Os estudos de arqueologia demonstram que os antigos as usavam como alimento há cerca de 6.000 anos. É uma noz deliciosa, produzida em grandes e magníficas árvores localizadas em grandes extensões de hábitat natural no Hemisfério Norte, especialmente na China, Coreia, Japão e sul da Europa. A noz é carnosa e doce com textura amilácea e baixo teor de gordura, semelhante a um grão de cereal. É um alimento tradicional em grande parte da Ásia e da Europa, onde é consumida fresca, cozida, assada, cristalizada e como fonte de farinha para pastelaria.

A domesticação da castanha ainda está progredindo, sendo que grande parte da produção mundial é coletada de povoamentos naturais, que consistem em indivíduos de espécies puras ou, mais comumente, como híbridos de diferentes espécies, porque eles prontamente cruzam uns com os outros. Em muitos casos, é difícil distinguir as espécies e quase impossível de determinar visualmente a paternidade dos híbridos.

A castanheira tem sido muito apreciada pela boa qualidade de seus frutos, a alta tolerância ao estresse ambiental e a sua adaptação, dependendo da origem genética, desde climas temperados até climas mais quentes. Sendo atualmente cultivadas em regiões subtropicais da China, Austrália, Nova Zelândia e Brasil, com êxito. Na China, os cultivos vão desde os climas temperados, localizados nas coordenadas $40^{\circ} 26^{\prime} \mathrm{N}$, até as regiões subtropicais a $18^{\circ} 30^{\prime} \mathrm{N}$, cobrindo 24 províncias.

Na Nova Zelândia e Austrália, é cultivada em grande extensão, onde não existem muitos problemas com pragas e doenças, por conta de um severo programa de introdução de material genético para a prevenção de entradas de pragas. As plantações são baseadas em seleções de castanheiras derivadas de cultivares euro-japoneses e seus híbridos.

Por estarem próximo à Ásia e capaz de fornecer castanhas frescas no período de entressafra, é uma vantagem competitiva para os produtores de castanha australianos.

Na Austrália, é incentivado o crescimento da indústria de castanha através do treinamento de produtores, promoção, pesquisa e compartilhamento de informações. As associações têm como objetivo ajudar os membros com informações em primeira mão sobre o cultivo, a colheita e a comercialização de castanhas.

Nas últimas décadas, o interesse pelo consumo e cultivo das castanhas gerou um incremento na pesquisa, visto que ocorreram quatro simpósios internacionais sobre a castanha. Todo esse trabalho certamente auxiliou no aumento da produção de castanhas no mundo, as quais se expandiram de forma significativa no período de 1995 a 2010, com um aumento significativo no total produzido, que passou de 690 mil toneladas para 1.866 mil toneladas. A China é o maior produtor e a que apresentou a maior taxa de crescimento no período. Nota-se que Portugal, Itália e Espanha, que são os nossos fornecedores de castanhas, não obtiveram aumento na produção (Tabela 1). Em Portugal, a maioria dos cultivos é de pequenos produtores, que fornecem as frutas para grandes empresas exportadoras. Essas empresas são detentoras de equipamentos e mão de obra necessária ao processamento das frutas para a comercialização.

Os países produtores são, ao mesmo tempo, os principais consumidores, sendo que o comércio internacional de castanhas é pequeno frente à produção mundial. Embora pertençam ao grupo dos principais produtores, França e Japão são importadores. Sendo que os países que não pertencem ao grupo dos principais produtores absorveram a maioria do total das importações, e inclui-se nesse grupo o Brasil (Tabela 2).

$\mathrm{Na}$ última década, ocorreram acentuadas reduções nos volumes importados pelo País, que chegou a atingir 2.732 toneladas em 1997 e caiu para 1.522 toneladas em 2005 (-44,3\%). Simultaneamente, os valores médios das toneladas de castanha importada oscilaram entre o mínimo 
de US\$ 1.500 (em 1999) e o máximo de US\$2.430 (em 2005). Assim, entre esses dois períodos, as importações brasileiras de castanha apresentaram queda de $46 \%$ na quantidade média e aumento de $165 \%$ no preço médio cotado em real. De 2004 a 2010, não ocorreram grandes mudanças no volume importado pelo Brasil, o que pode representar um aumento na produção de castanhas no Brasil (Tabela $3)$.

As importações brasileiras de castanha provêm basicamente de Portugal $(98,5 \%)$, cabendo apenas 1,5\% à Espanha (dados de 2005, SECEX, 2007).

Conforme as informações da CEAGESP em São Paulo, em 2005, indicam que $60 \%$ da castanha comercializada no entreposto foi oriunda de importações (representando 10\% das importações brasileiras) e $23 \%$ referiram-se a transferências entre CEASAs. O volume restante (17\%) proveio basicamente de produtores localizados em municípios paulistas, respondendo o Estado do Paraná por apenas $0,01 \%$ do total comercializado.

As grandes redes de supermercados são os maiores importadores e mantêm, inclusive, um sistema de auditoria para conferir, junto aos produtores e casas embaladoras, a qualidade das castanhas que serão exportadas para o Brasil. As características observadas pelos auditores brasileiros são:

- calibre das frutas;

- aspecto externo das frutas: sujidade, rachaduras podridões e manchas;

- aspecto interno das frutas: presença de larvas vivas e mortas, podridões e textura da polpa.

As frutas que alcançam os maiores preços são as de calibre cujo número de frutas por quilo não passa de 60. Em Portugal, as frutas menores, mais que 100 frutas por quilo, são descascadas e congeladas para serem comercializadas durante a entressafra da Europa, de janeiro a setembro. Na China, as castanhas menores servem para o processamento, inclusive cozidas, torradas e embaladas a vácuo.

Os sistemas vigentes para a classificação das castanhas, a nível internacional, baseiam-se em dois sistemas: o francês e o italiano. No sistema francês, as frutas de ótima qualidade, com taxas inferiores a $12 \%$ de poliembrionia, são classificadas como "marrom"; do contrário, as frutas são classificadas como castanhas. Pelo sistema italiano, uma cultivar de ótima qualidade classifica-se como "marrom", quando são cumpridos os seguintes atributos: número inferior a 80 frutas por $\mathrm{kg}$, pericarpo de cor café-claro com estrias escuras no sentido longitudinal, forma oval alargada, pericarpo delgado com tegumento interno que não penetre na massa comestível e que se destaque facilmente, polpa doce, de consistência cremosa e que não se altere no processo de cozimento.

\section{CULTIVO E CONSUMO NO BRASIL}

Desde sua introdução no País, a maioria das plantas foi propagada por sementes, incrementando a variabilidade de indivíduos, devido a ser uma espécie altamente heterozigota.

No município de São Bento do Sapucaí, no final da década de 60, o Sr. Giuseppe Sadun reflorestou sua fazenda com eucalipto, pínus e castanheiras, como terceira opção. Plantou cerca de 1.000 plantas. Na época, ele decidiu experimentar as variedades trazidas do Japão, que foram introduzidas pelo agrônomo Keiji Matsumoto, de São Paulo. Assim metade de seu cultivo foi composto por árvores de produção precoce, ou seja, a colheita inicia-se a partir de meados de novembro. O pomar era conduzido pelo funcionário da CATI, o Sr. Alvarino Ribeiro de Paula, que também ajudou a implantar outros castanhais na região, inclusive no Núcleo de Produção de Mudas São Bento do Sapucaí.

$\mathrm{Na}$ década de 80, o Engenheiro Agrônomo Takanoli Tokunaga, então diretor do Núcleo de Produção de Mudas, iniciou uma série de atividades com o objetivo de produzir mudas de qualidade e gerar tecnologia adaptada às nossas condições, para o cultivo das castanhas.

Atualmente, na coleção de castanheiras do Núcleo de Produção de Mudas São Bento do Sapucaí, constam as seguintes cultivares de Castanea crenata:

- Km-2, Tiodawase, Morioase, Isumo, Ibuki, Km-1, Kinshu, Tamatsukuri, Okuni, Taishowase, Senry, Tanzawa, Tsukuba, Ishizuchi, Kunimi, Hakuri, Ginyose, sendo estas 5 últimas cultivares de alta qualidade e que estão sendo cultivadas há vários anos na região sul de Minas com sucesso. Existem algumas seleções realizadas na região que têm ótimo potencial. Dentre elas, a Km1 e KM2, foram selecionadas pelo Sr. Keiji Matsumoto, em São Bento do Sapucaí-SP, e de cultivares de Castanea sativa.

- $\quad$ Paragon e uma seleção local denominada Jacutinga, esta última com características de Castanea sativa, produzindo, em janeiro e fevereiro, castanhas doces, grandes, sem poliembrionia, e facilidade para a retirada da casca externa e a película interna, em janeiro e fevereiro (Figura 1).

Uma seleção feita pelo Sr. Amagai, no Sul de Minas, tem ótimas características, como tamanho, castanhas com peso médio de $38 \mathrm{~g}$, ausência de 
poliembrionia, bom sabor, boa produtividade e facilidade de retirada da membrana interna (Figura 2).

Atualmente, em São Paulo, existem pomares comerciais com mais de 20 anos de idade em Arapeí, Campinas, Campos do Jordão, Cunha, Itupeva, Itapecerica da Serra, Mogi Mirim, Piedade, Pindamonhangaba, Santo Antônio do Pinhal, São Bento do Sapucaí, São José dos Campos e Taubaté. Em Minas Gerais, os pomares comerciais estão localizados na região Sul do Estado, em Brazópolis, Conceição dos Ouros, Espírito Santo do Dourado e Pouso Alegre, Jacutinga e Gonçalves.

\section{PROPAGAÇÃO}

Devido à ocorrência de polinização cruzada, as plantas procedentes de sementes são desuniformes quanto ao tamanho, tipo e vigor, o que é inaceitável em uma produção comercial. A produção de frutos também é variável no tamanho, cor, sabor, etc.

Aqui no Brasil, comercialmente, as castanheiras são produzidas através de enxertia por garfagem, sobre porta-enxertos de um ano de idade, provenientes de plantas de variedades compatíveis com o enxerto (BUENO et al., 2002). Pois, a enxertia entre variedades diferentes apresenta diferentes níveis de incompatibilidade, que se manifesta de várias formas, desde o não pegamento do enxerto, na fase de produção de mudas, à produção de árvores de pequeno porte e anãs, ou mesmo a morte de plantas após o plantio no local definitivo, por um período de até 15 anos após o plantio. Vale ressaltar que a produção de plantas pequenas viabiliza o espaçamento adensado.

Os garfos são coletados quando as gemas estão diferenciadas e maduras, e em algumas cultivares como a Taishowase ocorre a abscisão das gemas basais, então tem que se coletar os garfos antes desse processo, o que acontece em São Bento do Sapucaí-SP, cujo clima é Cwb, latitude $22^{\circ} 41^{\prime} \mathrm{S}$ e longitude $45^{\circ} 44^{\prime} \mathrm{W}$, de maio a junho, dependendo do ano. Nessas condições, para as cultivares existentes, a enxertia pode ser feita imediatamente após a coleta do material, por conta de as gemas já terem recebido uma quantidade de frio e o inverno não ser muito rigoroso (BUENO et al., 2009).

A enxertia por borbulhia pode ser realizada com sucesso. A estaquia e a cultura de tecidos são possíveis, porém ainda apresentam dificuldades.

\section{Produção de porta-enxertos}

As sementes são coletadas assim que caem e cuidadosamente selecionadas, separando as manchadas, as brocadas, as rachadas e as chochas. As sementes selecionadas e tratadas são semeadas superficialmente, com a parte reta para baixo, em canteiros de areia, uma ao lado da outra, dentro de estufas. Por volta de 30 dias, as sementes começam a emitir a radícola, quando se procede ao transplantio para o campo ou para recipientes.

Os recipientes onde as sementes serão transplantadas devem ser cheios, pelo menos, uns três meses antes. Esta prática foi concebida baseando-se na grande dependência endomicorrízica da espécie.

\section{Implantação do castanhal}

Vários fatores devem ser levados em consideração para a instalação do castanhal, destacando-se a irradiância, ou seja, a luz solar interceptada por unidade de área e a localização da casa embaladora. Quanto mais perto estiver o recebimento das castanhas por ocasião da colheita, menor será o custo de transporte e melhor a qualidade pós-colheita, uma vez que se trata de frutos perecíveis.

As castanheiras preferem solos bem drenados, com $\mathrm{pH}$ ao redor de 5,5 a 6,5 e são relativamente resistentes a ventos, quando comparadas com outras fruteiras. A ocorrência de geadas no início da brotação é prejudicial à produção. As chuvas regulares durante o período de florescimento e de crescimento dos frutos contribuem para se obter castanhas de bom tamanho, e desta forma a irrigação suplementar, nesses estágios, pode ser benéfica em alguns casos.

$\mathrm{Na}$ maturação dos frutos, temperaturas ao redor de 25 a $30^{\circ} \mathrm{C}$ são favoráveis. Por ser uma planta originária de clima temperado, tendo que passar por um período de dormência, a produção de frutos é melhor em locais onde haja um período do ano sem chuvas e com temperaturas amenas. No Estado de São Paulo, alguns castanhais, com 20 anos de idade, localizados a $550 \mathrm{~m}$ de altitude, no Vale do Paraíba, têm apresentado bons resultados. 
TABELA 1- Produção de castanha (Castanea ssp.) nos principais países produtores, em 1995, e de 2000 a 2010 (em toneladas).

\begin{tabular}{cccccccc}
\hline Pais & 1995 & 2000 & 2002 & 2004 & 2006 & 2008 & 2010 \\
\hline China & 300.000 & 598.185 & 701.684 & 922.735 & 1.139 .660 & 1.450 .450 & 1.550 .000 \\
Coreia do Sul & 93.655 & 92.844 & 72.405 & 71.795 & 82.450 & 75.171 & 68.630 \\
Turquia & 77.000 & 50.000 & 47.000 & 49.000 & 53.814 & 55.395 & 59.171 \\
Itália & 71.971 & 50.000 & 54.315 & 39.976 & 52.615 & 55.000 & 42.700 \\
Bolivia & 31.229 & 34.400 & 46.000 & 52.758 & 55.000 & 58.442 & 53.577 \\
Portugal & 23.238 & 33.317 & 31.385 & 31.051 & 30.900 & 21.990 & 22.400 \\
Japão & 34.400 & 26.700 & 30.100 & 24.000 & 23.100 & 25.300 & 23.500 \\
Grécia & 12.053 & 15.303 & 15.200 & 18.712 & 17.442 & 9.800 & 20.900 \\
França & 11.016 & 13.224 & 11.223 & 12.431 & 9.670 & 6.290 & 9.536 \\
Coreia do Norte & 7.500 & 8.433 & 9.688 & 9.000 & 8.000 & 10.500 & 10.700 \\
Espanha & 10.075 & 9.230 & 9.362 & 9.510 & 10.140 & 10.000 & 5.100 \\
TOTAL & & & & & & & 1.866 .214
\end{tabular}

Fonte: FAOSTAT, 2012.

TABELA 2- Consumo aparente ${ }^{1}$ e exportação líquida ${ }^{2}$ de castanha (Castanea sp.) nos principais países produtores e no mundo, em 2010 (em tonelada).

\begin{tabular}{cccccc}
\hline País & Produção & Importação & Exportação & $\begin{array}{c}\text { Consumo } \\
\text { aparente }\end{array}$ & $\begin{array}{c}\text { Exportação } \\
\text { liquida }\end{array}$ \\
China & 1.620 .000 & 17.355 & 37.099 & 1.600 .256 & 19.744 \\
Coreia do Sul & 68.630 & 0 & 12.584 & 56.046 & 12.584 \\
Itália & 48.810 & 6.770 & 18.936 & 36.644 & 12.166 \\
Turquia & 59.171 & 247 & 3.073 & 56.345 & 2.826 \\
Bolívia & 53.577 & 1 & 1.801 & 51.777 & 1.800 \\
Portugal & 22.350 & 1.473 & 6.842 & 16.981 & 5.369 \\
Japão & 23.500 & 12.625 & 1.747 & 34.378 & -10.878 \\
Rússia & 0 & 43 & 0 & 43 & -43 \\
Grécia & 20.900 & 78 & 184 & 20.794 & 106 \\
França & 9.351 & 7.978 & 2.979 & 14.350 & -4.999 \\
Espanha & 5.086 & 2.051 & 6.776 & 361 & 4.725 \\
Coreia do Norte & 9.628 & 1.337 & 0 & 10.965 & -1.337 \\
\hline
\end{tabular}

${ }^{1}$ Produção mais Importação menos Exportação.

${ }^{2}$ Exportação menos Importação.

Fonte: FAOSTAT, 2012.

TABELA 3- Volume (kg) e Valores (US\$) das Importações Brasileiras de Castanhas, de 2004 a 2010.

\begin{tabular}{lccccccc}
\hline \multirow{2}{*}{ Volume } & 2004 & 2005 & 2006 & 2007 & 2008 & 2009 & 2010 \\
& 1.372 .250 & 1.521 .686 & 1.937 .742 & 1.779 .581 & 1.207 .662 & 1.732 .101 & 1.851 .143 \\
Valores & 2.918 .957 & 3.753 .590 & 4.460 .955 & 6.581 .829 & 4.033 .335 & 6.043 .340 & 5.917 .215 \\
\hline
\end{tabular}

Fonte: IBRAF 2012 


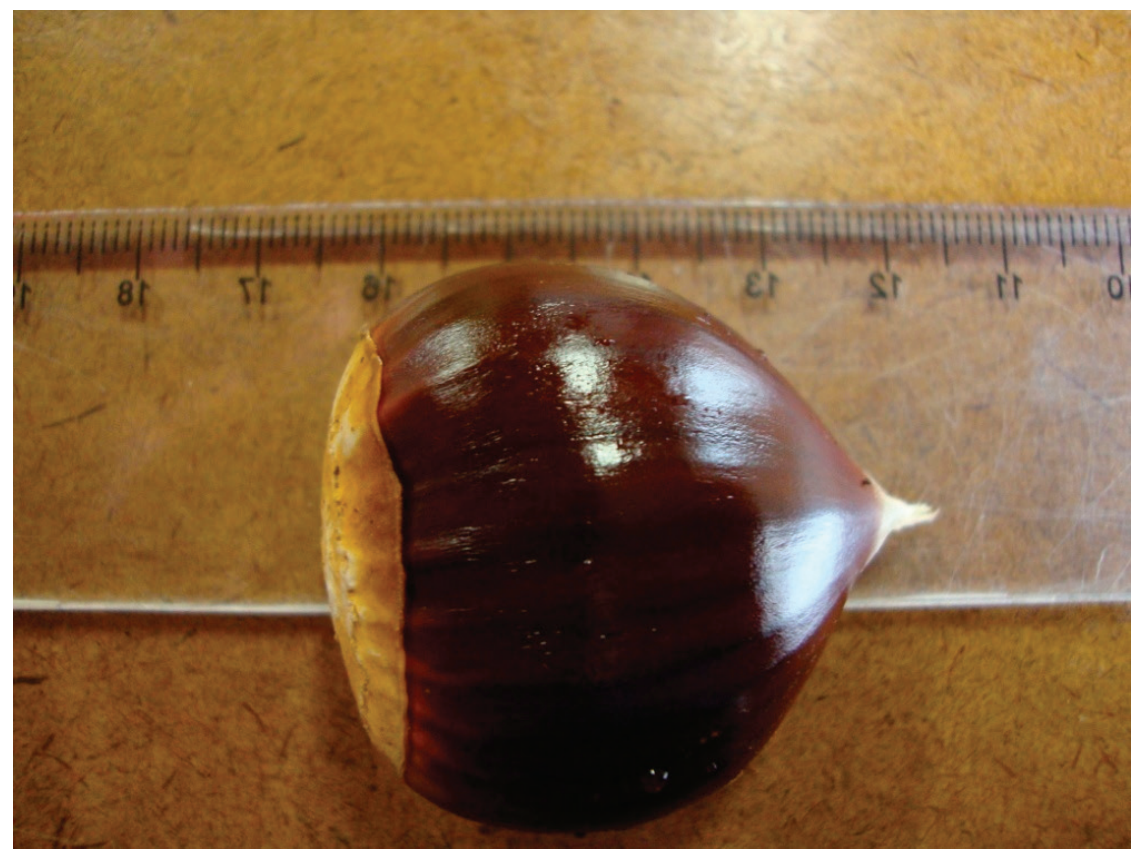

FIGURA 1- Castanha Jacutinga.

Foto: Silvana Catarina Sales Bueno.

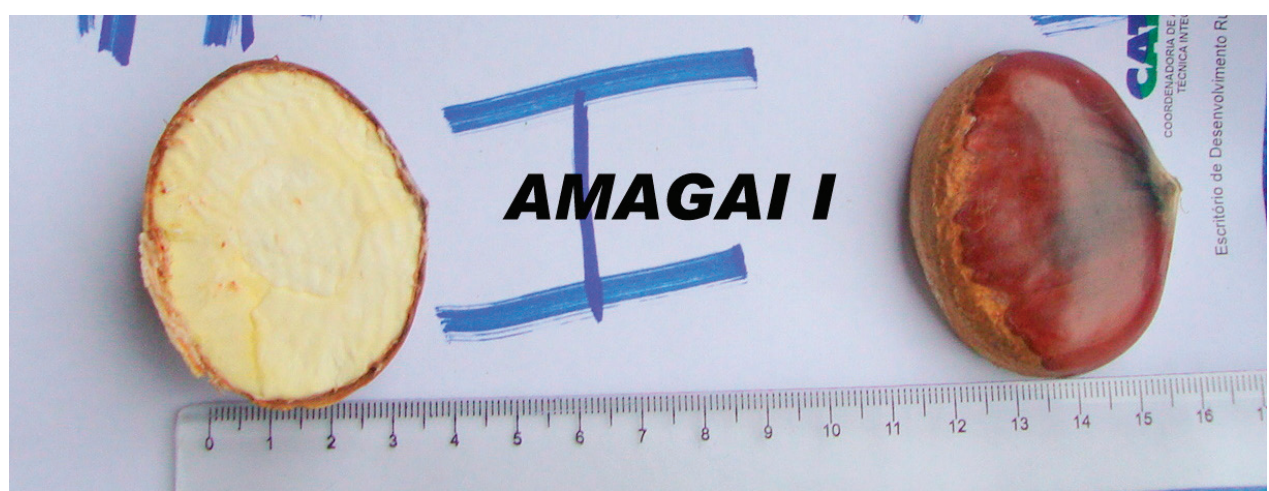

FIGURA 2- Seleção de castanheiras-japonesas realizada pelo Sr. Isashi Amagai, em Pouso Alegre-MG. Foto: Silvana Catarina Sales Bueno. 


\section{CONSIDERAÇÕES FINAIS}

O potencial mercadológico da castanha deve ser percebido pelo empresário brasileiro das frutas como fonte rentável.

Além disso, a produção brasileira das principais espécies frutíferas de clima temperado é insuficiente para atender à demanda interna, gerando uma crescente necessidade de importação de frutas que podem ser produzidas no Brasil.

A queda nas importações de castanhas, nos últimos 10 anos, não pode ser vista como uma tendência de decréscimo no consumo brasileiro, pois a procura por mudas de castanhas no País tem aumentado, denotando a expansão dos cultivos. Entretanto, a evolução nos preços das importações foi acentuadamente desfavorável aos consumidores brasileiros, principalmente quando se consideram os preços das importações cotados na moeda nacional, em real.

Há que se ressalvar, contudo, que o estímulo à produção interna de castanha deve ser realizado com base em estudos que abordem todos os segmentos da cadeia produtiva do produto, desde o material genético até o processamento e a comercialização, de forma a proporcionarem importantes elementos para o desenvolvimento sustentável da atividade. Nesse sentido, o Núcleo de Produção de Mudas de São Bento do Sapucaí vem realizando uma série de ações técnicas e pesquisas em parceria com a Universidade Federal de Lavras (UFLA), visando a quantificar a composição química das cultivares, a biometria dos frutos, bem como os trabalhos de propagação.

Para qualquer introdução de materiais, devem-se ter maiores precauções, obedecendo a todas as normas quarentenárias, pois, pragas e doenças existentes em outros países praticamente dizimaram as culturas, em algumas regiões. Essas pragas não existem aqui, e isso nos coloca em grande vantagem diante de muitos.

Nesse sentido, é imprescindível o levantamento e a disponibilização de número maior de informações sobre a atividade no País, essenciais para subsidiar as tomadas de decisões dos integrantes da cadeia produtiva, além de introdução de materiais avançados e a organização dos produtores, para sustentar, viabilizar e aplicar todo esse processo.

\section{REFERÊNCIAS}

BUENO, S.C.S. Castanha tipo portuguesa. Campinas: CATI, 2004. 42p. (Boletim Técnico, 246).

BUENO, S.C.S.; COUTINHO, E.; MAIA, A.H.; YAMANISHI, O. Grafting compatibility among eleven chestnut cultivars and hybrids. Acta Horticulturae, The Hague, v.844, p.127-131, 2009.

BUENO, S.C.S.; BERTI, A.J.; BLAT, S.F.; TOGUNAGA, T. Compatibilidade da Enxertia de 11 Híbridos de Castanheira (Castanea crenata $\times$ Castanea sp.) sobre 10 porta enxertos. In: CONGRESSO BRASILEIRO DE FRUTICULTURA, 17., 2002, Belém. Anais... p. 10-14.

\section{FAOSTAT. Food And Agriculture Organization Of}

The United Nation. 2012. Disponível em: $<\underline{w w w}$. faostat.fao.org $>$. Acesso em: mar. 2013.

IBRAF - Instituto Brasileiro de Frutas. 2012. Disponível em: <www.ibraf.org.br>. Acesso em: mar. 2013.

MARO, L.A.C.; PIO, R.; PENONI, E.S.; OLIVEIRA, M.C.; PRATES, F.C. ; LIMA, L.C.O.; CARDOSO, M.G. Caracterização química e perfil de ácidos graxos em cultivares de nogueira-macadâmia. Ciência Rural, Santa Maria, v.42, n.12, p.21662171, 2012.

MAYNARD, C.A.; POWELL, W.A.; POLINMCGUIGAN, L.D.; VIÉITEZ, A.M.; BALIESTER, A.; CORREDOIRA, E.; MERKLE, S.A.; ANDRADE, G.M. Chestnut. In: KOLE, C.; HAN. T.C. (Ed.). Compendium of transgenic crop plants: transgenic forest tree species. Hoboken: Wiley, 2008. p.169-192.

PENONI, E.S.; PIO, R.; RODRIGUES, F.A.; MARO, L.A.C.; COSTA, F.C. Análise de frutos e nozes de cultivares de nogueira-macadâmia. Ciência Rural, Santa Maria, v.41, n.12, p.2080-2083, 2011. 